\title{
Challenges Facing the Organization of Tourism Programs to Jordan
}

\author{
Mohammad Nayef Alsarayreh ${ }^{1}$ \\ ${ }^{1}$ Al-Balqa Applied University, Jordan \\ Correspondence: Mohammad Nayef Alsarayreh, Al-Balqa Applied University, Jordan. E-mail: \\ mohammad_n_k_s@yahoo.com \\ Received: July 27, 2018 \\ Accepted: September 26, 2018 \\ Online Published: October 12, 2018 \\ doi:10.5539/ijbm.v13n11p192 \\ URL: https://doi.org/10.5539/ijbm.v13n11p192
}

\begin{abstract}
Aims to study the problems facing the organization of tourism programs to Jordan and identified a number of the most prominent problems to be studied.

The study was based on preliminary sources, where information was collected from samples of tourism and travel companies in Jordan, and the problems of organizing tourist programs were investigated.

The study is based on a set of hypotheses that the work in the tourism sector is facing problems to organize tourism programs in the fields of study mentioned above and there are statistically significant differences in degree of exposure to the problems of organizing tourism programs due to the variables of work field and work volume. This research was followed by descriptive analytical approach, which aims to study the problems of organizing tourism programs to Jordan.
\end{abstract}

The study found the following results:

- Decrease in the number of tourists because of the political conditions that are affecting the region and which have a significant impact on the tourism sector and tourism programs

- The role of media and exaggeration and not to investigate the truth in the transfer of the real picture in the region in general.

Keyword: challenges, organization, tourism program

\section{Introduction}

The tourism sector is considered one of the most important economic sectors in Jordan, It shows the importance of tourism as a source of income in a country that is not rich in natural resources. In most countries of the world that rely on tourism as a source of income, the most important thing is to introduce the tourist to a beautiful experience that he remembers throughout his life, He will return to visit the country in the future, or at least tell his friends and family what he has seen and experienced Tourist year after year Although Jordan is characterized by its possession of archaeological treasures, especially Petra, one of the seven wonders of the world, but unfortunately, most statistics on tourism in Jordan indicate that most tourists that come once do not come back again . Tourism has become a critical sector of the Jordanian economy and the sector still has the potential to promote overall economic growth as well as push for employment and income generation for the population. Areas identified with government intervention include improving the business environment, focusing on specific geographical areas, focusing on sectors that have the greatest impact on mitigation Poverty and export potential as well as public and private sector participation in joint investment. Jordan enjoys a good position to move from being a regional tourist destination within multiple countries to a stand-alone destination with a range of attractive tourism products Year visitors to foreign and local visitors. This requires a long-term commitment to all public and private.

The Jordanian tourism sector achieved many positive indicators despite the unstable political and security situation in the region and the region. The Kingdom's tourism income rose to 2.989 billion dinars during the 11 months of 2017 compared to 2.650 billion dinars for the same period of 2016 , an increase of $12.8 \%$. This increase is a result of the increase in the number of tourists by $9 \%$ compared to the same period of 2016 . The total number of overnight tourists that entered the Kingdom during the period of 2017 was about 3.9 million tourists compared to about 3.6 million tourists for the same period of the year 2020. 


\subsection{The Study Problem}

The tourist sites suffer from ignoring the state in light of relying on traditional plans not studied scientifically and accurately and do not take into account the environmental dimensions of the nature of the tourist places required to be restricted and development and the means of attraction appropriate to them , in addition to low level of awareness and lack of interest in information systems in the field of tourism to introduce our tourism wealth, Weakness and inadequacy of tourism plans and their inadequacy with reality . The tourism sector lacks demands to understand the dimensions of the current and future developments in the global tourism market and prepare for them through the process of concentration and integration into larger entities that are able to work in all circumstances through modern planning which has become an important means to achieve development plans to raise the rates of tourism growth to achieve Tourism proceeds required.

\subsection{Objectives of the Study}

Aims to study the problems facing the organization of tourism programs to Jordan and identified a number of the most prominent problems to be studied are:

1. No destinations have been developed to attract and retain tourists for more than one day or overnight stay

2- Lack of recreational activities and secondary activities to stimulate regional, local and international tourism

3 - Lack of accommodation of two, three or four star stars in strategic places, which deters budget tourism and potential domestic tourism

\subsection{Research Methodology}

This research was followed by a descriptive analytical approach, which aims to study the problems of organizing tourism programs to Jordan, and to reach results that contribute to providing information that helps to develop and improve the organization of tourism programs in the Jordan region.

A total of 100 questionnaires were distributed and all questionnaires were retrieved and all were valid for statistical analysis.

\subsection{Study Tool}

The data collected from the study community were collected through a questionnaire which was prepared using the literature and previous studies. The questionnaire contained a set of questions divided into two parts:

Part I: This section deals with the data and personal information of the sample of the study sample, including (year of establishment, number of employees, type of office, educational level).

Part II: This part of the questionnaire included 24 questions to be answered by the tourism company official.

\subsection{Study Hypotheses}

The first hypothesis: There is no relationship between the problems of organizing tourism programs and administrative aspects.

The second hypothesis: There is no relationship between the problems of organizing tourism programs and the technical aspects.

The third hypothesis: There is no relationship between the year of establishment and the problems of organizing tourism programs resulting from both administrative and technical aspects.

\section{Previous Studies}

Hammad, Abdelkader Ibrahim, Obstacles to Tourism Development in Palestine The West Bank and the Gaza Strip: A Study in the Geography of Tourism.

This study seeks to identify the obstacles facing the tourism sector in the Palestinian territories as one of the vital sectors in Palestine and other countries that are now paying particular attention to this sector. Identifying these constraints can help identify future directions for the development of the tourism industry by developing solutions and programs that help guide tourism activity in the right direction. The study examined the results of the study on the obstacles to tourism development in Palestine, which were divided into security and political obstacles, financial and economic obstacles, administrative and organizational obstacles, obstacles to tourism planning, environmental constraints, Tourism Assistance. The study found that the political conditions experienced by the Palestinian territories in general constituted a major obstacle to the development of the tourism industry, despite the great importance of the Holy Land in the field of tourism movement, in addition to other obstacles such as the lack of laws governing the tourism industry in The Palestinian Territory, which is one of the most important organizational and administrative obstacles that limit the development of the tourism 
industry and recommended the study to develop a comprehensive strategy for the marketing of Palestine in various parts of the world, with the focus on the media, and the development of tourism services and work to raise the level with the encouragement of abstinence $\mathrm{R}$ in the tourism sector through tax cuts and encourage investors.

Bader Ayed Nimer,(2010) The role of marketing management in raising the efficiency of the performance of tourism services in Jordan.

If Jordan becomes one of the countries that are interested in tourism, this important sector, which strengthens the national economy and contributes to the increase of national income, there must be a role of marketing management as a concept of high importance taken into account. The aim of this research is to study the role of marketing management in raising efficiency The performance of tourism services in Jordan, study and analyze data and information on the reality of the Jordanian tourism industry and draw conclusions and recommendations that help and contribute in finding effective and appropriate solutions, which in turn improve the effectiveness of marketing management to improve the Jordanian tourism sector. O standard of living and contribute to the GNP of Jordan, The research problem is to identify the effectiveness of the marketing management of tourism services as it effectively affect the provision of Jordanian tourism product, came this research to contribute to the enrichment of the important topic in economic development.

Ismail Al-Dabbagh, (2011), Methods of calculation of tourism income Concerns between the theoretical and practical side constraints With particular reference to Iraq, The research aims at removing the entanglement and overlap between the concept of tourism income and the other concepts mentioned in tourism literature such as tourism revenue, tourism expenditure, tourism revenues, tourist receipts, tourism income, etc., and clarifying the difference between them according to economic logic, Tourism in Iraq according to the statistical possibilities available in official government records and the experiences of others. The research came in four directions, beginning with the concept of tourism income according to three groups (output, income, expenditure).

Mekdad, Mohamed Ibrahim,(2015) The reality of tourism in the Gaza Strip and the prospects for its development: Hotels as a case study.

This research aims at diagnosing the reality of tourism in the hotels of the Gaza Strip and finding out the factors affecting the tourism development in the Gaza Strip hotels. The contribution of the Palestinian direct tourism sector in the GDP is about 4\%, which is low compared with its counterparts in neighboring Arab countries. The research used several approaches to arrive at the test of hypotheses such as the historical approach in studying the development of tourism locally and internationally, and the analytical descriptive approach in presenting the reality of the tourism economy in Palestine especially the study area in the Gaza Strip. The method of statistical analysis was also used for surveying the opinions of the owners And the managers of tourist establishments operating in the Gaza Strip. The quantitative data were analyzed using SPSS.

\section{Statistical Analysis}

Based on our study, we obtained the following statistical analysis:

Stability of the tool:

* The stability of the tool was tested by the Cronbach Alpha test.

Table 1 shows that the value of alpha for the paragraphs of the first dimension related to the administrative aspects is 0.80 , that is, there is stability in the tool in relation to these paragraphs.

Table 1. Results of the Cronbach Alpha test for the first dimension of the administrative aspects:

\begin{tabular}{ll}
\hline Alpha value & Number of paragraphs \\
\hline 0.80 & 15 \\
\hline
\end{tabular}

In view of Table 2, which shows the value of alpha for the paragraphs of the second dimension related to technical aspects, we find that the value of alpha is 0.67 , that is, there is stability in the tool in relation to these paragraphs. 
Table 2. Results of the Cronbach Alpha Test for the second dimension related to technical aspects

\begin{tabular}{ll}
\hline Alpha value & Number of paragraphs \\
\hline 0.67 & 7 \\
\hline
\end{tabular}

Table 3 shows the value of alpha for all paragraphs, and the value of alpha 0.90 is that there is stability in the tool as a whole.

Table 3. The results of the Cronbach test for all the paragraphs combined

\begin{tabular}{ll}
\hline Alpha value & Number of paragraphs \\
\hline 0.90 & 26 \\
\hline
\end{tabular}

Description of the personal and functional variables of the offices:

First: Year of Establishment:

Table 4 shows that the oldest office was established in 1953 and the latest office was established in 2010.

Table 4. Frequency and percentage of variable Year of establishment

\begin{tabular}{lll}
\hline percentage \% & Repetition & Year Founded \\
\hline 3.3 & 1 & 1953 \\
3.3 & 1 & 1966 \\
3.3 & 1 & 1974 \\
3.3 & 1 & 1979 \\
3.3 & 1 & 1983 \\
3.3 & 1 & 1985 \\
3.3 & 1 & 2010 \\
\hline
\end{tabular}

Second: Number of employees

Table 5 shows that $30 \%$ of the offices employ 3-8 employees, $45 \%$ of the offices have 10 or more employees, $15 \%$ of offices have 3 or fewer employees, $10 \%$ of offices have 7 to 10 employees .

Table 5. Frequency and percentages of the variable number of employees

\begin{tabular}{lll}
\hline percentage $\%$ & Repetition & Number of Employees \\
\hline 15 & 15 & Equals or less than 3 \\
30 & 30 & $3-8$ \\
10 & 10 & $8-12$ \\
45 & 45 & More than 12 \\
\hline
\end{tabular}

Third: Type of office

Table 6 shows that $60 \%$ of the study sample is in category A and $40 \%$ in category B

Fourth: Educational Level

Table 6. Frequency and percentages of variable type of office

\begin{tabular}{lll}
\hline percentage $\%$ & Repetition & Office type \\
\hline 60 & 60 & Class A \\
40 & 40 & Class B \\
-- & --- & Class C \\
\hline
\end{tabular}

Table 7 shows that $30 \%$ of the offices are managed by managers of diploma holders $60 \%$ are from secondary school, 20\% are BA holders. 
Table 7. Frequency and percentage of the educational variable

\begin{tabular}{lll}
\hline percentage $\%$ & Repetition & Educational level \\
\hline $\mathbf{3 0}$ & $\mathbf{3 0}$ & secondary \\
$\mathbf{5 0}$ & $\mathbf{5 0}$ & diploma \\
$\mathbf{2 0}$ & $\mathbf{2 0}$ & BA \\
--- & -- & M.A. \\
\hline
\end{tabular}

Testing hypotheses and analyzing results:

The first hypothesis: There is no relationship between the problems of organizing tourism programs and administrative aspects.

Table 8 shows:

1. Paragraphs 5, 6, 7, 11, 13 have obtained an arithmetic mean greater than 1.00, and the levels of significance of each of them are less than 0.05 , meaning that all these issues constitute problems of organizing tourism programs to Jordan.

Paragraph 5, which measures the non-response of tourists to the hotels of 4, 3 stars lack of beaches, ranked first and with an average of 1.76 , the lack of beaches for hotels 3 , and 4 stars is the most important problems.

Paragraph 7, which measures the extent to which the rise in prices of services in Jordan caused the lack of tourists to Jordan, ranked second. Paragraphs 17, 18, 12 came in third, fourth and fifth respectively

2. Paragraphs 3 and 13 Although they obtained two separate accounts of greater than 1.00, the respective levels of significance were greater than 0.05 . That is, it is not statistically significant.

3. The combined paragraphs reached the mean of 1.06 and the level of significance is 0.29 which is greater than 0.01 there are no problems resulting from administrative aspects.

Table 8. The arithmetic mean, the standard deviation, the $\mathrm{t}$ value, and the level of significance of the administrative aspects

\begin{tabular}{|c|c|c|c|c|c|}
\hline $\begin{array}{l}\text { Observed } \\
\text { significance } \\
\text { level }\end{array}$ & $\begin{array}{c}\text { T- } \\
\text { value }\end{array}$ & $\begin{array}{l}\text { standard } \\
\text { deviation }\end{array}$ & $\begin{array}{l}\text { Arithmetic } \\
\text { average }\end{array}$ & Paragraph & No. \\
\hline 0.010 & $3.666-$ & 0.700 & 0.500 & $\begin{array}{l}\text { From your point of view, the lack of tourist demand is a low level of } \\
\text { tourist service. }\end{array}$ & 1 \\
\hline 0.211 & $0.856-$ & 0.755 & 0.544 & $\begin{array}{l}\text { The lack of tourism programs is the reason for the lack of demand for } \\
\text { foreign tourists to Jordan }\end{array}$ & 2 \\
\hline 0.623 & $0.321-$ & 0.6584 & 0.822 & The lack of tourists in Jordan is due to the lack of classified hotels & 3 \\
\hline 0.001 & $1.658-$ & 0.6548 & 0.510 & The lack of tourists in Jordan due to the lack of popular hotels & 4 \\
\hline 0.001 & 5.236 & 1.3265 & 0.258 & $\begin{array}{l}\text { The lack of tourist demand for hotels of } 4,3 \text { stars caused by the lack of } \\
\text { beaches }\end{array}$ & 5 \\
\hline 0.010 & 3.659 & 1.3659 & 2.456 & The lack of direct flights to Jordan is affecting tourists & 6 \\
\hline 0.001 & 6.325 & 0.2365 & 5.326 & $\begin{array}{l}\text { The high prices of services in Jordan is a reason for the lack of tourists in } \\
\text { the city }\end{array}$ & 7 \\
\hline 0.020 & $2.258-$ & 0.2369 & 0.236 & $\begin{array}{l}\text { One of the reasons for the lack of tourists in Jordan is the lack of } \\
\text { sufficient tourist guides }\end{array}$ & 8 \\
\hline 0.321 & 0.235 & 0.3698 & 1.254 & $\begin{array}{l}\text { From the point of view of travel and tourism companies the lack of high } \\
\text { demand for tourists tax rate }\end{array}$ & 9 \\
\hline 0.289 & $1.321-$ & 0.3269 & 0.369 & $\begin{array}{l}\text { The reason for the lack of tourists in Jordan is the high cost of } \\
\text { transportation }\end{array}$ & 10 \\
\hline 0.100 & 4.328 & 0.9632 & 1.329 & From your own point of view, tourists are exploited by taxi drivers & 11 \\
\hline 0.005 & 6.324 & 0.8974 & 1.236 & $\begin{array}{l}\text { From your point of view, and generally speaking, the locals see the } \\
\text { tourists positively }\end{array}$ & 12 \\
\hline 0.007 & 1.235 & 0.8963 & 0.234 & $\begin{array}{l}\text { From your point of view, and generally speaking, do local people view } \\
\text { tourism positively }\end{array}$ & 13 \\
\hline 0.80 & 0236 & 0.368 & 1.265 & Total & \\
\hline
\end{tabular}


The second hypothesis: There is a relationship between the problems of organizing tourism programs and technical aspects

* (Note that the wording of the questions in the paragraphs that are technical aspects is a positive formula, which is the opposite of the administrative aspects).

Table 9 shows that:

1. With the exception of paragraph 6 , all the other paragraphs have obtained an arithmetic mean greater than 2.00 , and the levels of significance of the scenes are less than 0.05 , meaning that all these issues do not constitute problems of organizing tourism programs to Jordan.

Paragraph 1, which measures the organization of optional travel programs for tourists in Jordan by travel and tourism companies, ranked first and averaged 1.90 .

Paragraph 7 came second, paragraph 2 was third, paragraph 9 was fourth, paragraph 24 was fifth, paragraph 4 was sixth, paragraph 6 was seventh, and paragraph 3 was last.

2 , while paragraph 6 , although it obtained a mean of greater than 0.00 , the level of significance shown was greater than 0.00 ., it is not statistically significant, that is to say that the lack of tourists in Jordan due to lack of publicity, is a problem to organize tourism programs to Jordan from the perspective of travel companies.

3 - The combined paragraphs, which represent the technical aspects, the arithmetic mean of 1.50 and the level of significance seen less than 0.05 , that is, there is no relationship of statistical significance between the technical aspects and the problems of organizing tourism programs.

Table 9. The arithmetic mean, the standard deviation, the value of $t$, and the level of significance of the administrative aspects

\begin{tabular}{|c|c|c|c|c|c|}
\hline $\begin{array}{l}\text { Observed } \\
\text { significance } \\
\text { level }\end{array}$ & T-value & $\begin{array}{l}\text { standard } \\
\text { deviation }\end{array}$ & $\begin{array}{l}\text { Arithmetic } \\
\text { average }\end{array}$ & Paragraph & No. \\
\hline 0.001 & 10.325 & 0.21468 & 1.3253 & $\begin{array}{l}\text { Your companies are organizing optional travel programs for } \\
\text { tourists in Jordan. }\end{array}$ & 1 \\
\hline 0.010 & 8.3216 & 0.5478 & 1.3269 & Your company organizes diving programs in the city for tourists & 2 \\
\hline 0.100 & 6.3217 & 0.3214 & 1.2547 & Your companies work on short stay programs & 3 \\
\hline 0020 & 7.369 & 0.3269 & 0.3214 & $\begin{array}{l}\text { Your companies will organize a visit to the city of Jordan within } \\
\text { contracted programs }\end{array}$ & 4 \\
\hline 0.001 & 8.9654 & 0.3215 & 1.9540 & Foreign tourists return to visit Jordan & 5 \\
\hline 0.010 & 0.658 & 0.3214 & 1.8796 & $\begin{array}{l}\text { In view of the lack of publicity, the lack of tourists in Jordan is } \\
\text { considered to be a lack of publicity. }\end{array}$ & 6 \\
\hline 0.020 & 9.8745 & 0.3698 & 1.5473 & Tourism and travel companies attract foreign tourists to Jordan & 7 \\
\hline 0.000 & 7.235 & 0.3698 & 1.3256 & $\begin{array}{l}\text { In your opinion, is the number of foreign tourists expected to } \\
\text { increase in the future to Jordan? }\end{array}$ & 8 \\
\hline 0.00 & 19.321 & 0.366 & 1.9876 & Total (artistic side) & \\
\hline
\end{tabular}

\section{Results}

The study found the following results:

1 - Decrease in the number of tourists because of the political conditions that are affecting the region and which have a significant impact on the tourism sector and tourism programs

2 - The role of media and exaggeration and not to investigate the truth in the transfer of the real picture in the region in general.

3- Weak cooperation between official and private bodies in activating tourism and taking the necessary measures to activate tourism.

4 - Lack of cooperation of tourism sectors in the creation of competitive tourism programs in the region around Jordan.

5- Lack of and inadequate services needed by tourists on the roads leading to tourist sites. 


\section{Recommendations}

1. The study recommends facilitating the acquisition of tourist visas.

2. The study recommends working on special offers at the prices of airline tickets.

3- The study recommends working on the prices of services in hotels.

4- The study recommends working on encouraging offers in tourism.

5. The study recommends increasing the promotion of Jordan as a global tourist destination.

\section{References}

Abdul, N. H. (2009). Tourism and hotel marketing, the problems of internal tourism. Dar books for printing and publishing.

Abed, A., \& Jabber, T. (1996). The importance of tourism in the Jordanian economy. Environmental Foundation in Jordan, Amman.

Arabiyat, T. et al. (2009). Problems of the Transition to Electronic Commerce in Tourism Business in the Jordan Region. University College of Jordan, Balqa Applied University, Jordan.

Bader Ayed Nimer,(2010). The role of marketing management in raising the efficiency of the performance of tourism services in Jordan. PhD Thiess, Sudan.

Hammad, A. I. (2013). Obstacles to Tourism Development in Palestine The West Bank and the Gaza Strip: A Study in the Geography of Tourism. Jordanian Journal of Social Sciences, 6(2), 240-265

Ismail, A. D. (2011). Methods of calculation of tourism income Concerns between the theoretical and practical side constraints With particular reference to Iraq. Journal of Administration and Economics, 89, 235-258.

Khateer, H. (2007). Human resources management (1st ed.). Amman: Dar Al musarah for Publishing and Distribution.

Mekdad, M. I. (2015). The reality of tourism in the Gaza Strip and the prospects for its development: Hotels as a case study. Journal of the Islamic University for Economic and Administrative Studies, 23(1), 41-73.

Ruby, N. (1984). Tourism Economics. Cultural Foundation, University Publishing, Alexandria, Egypt.

Yasser, S. (2003). School administration. House of world culture, Amman-Jordan..

\section{Copyrights}

Copyright for this article is retained by the author(s), with first publication rights granted to the journal.

This is an open-access article distributed under the terms and conditions of the Creative Commons Attribution license (http://creativecommons.org/licenses/by/4.0/). 